\title{
Differential Information, Arbitrage, and Subjective Value
}

\author{
Catherine Greene ${ }^{1}$ (이
}

Published online: 27 June 2019

(c) The Author(s) 2019

\begin{abstract}
de Bruin et al. (in: Zalta (ed) The Stanford encyclopedia of philosophy, Stanford University, Stanford, 2018) write that it is a philosophically interesting question "whether there is such a thing as an "intrinsic" value of financial assets" noting that the calculation of any intrinsic price will depend, in part, on subjective elements. McCauley suggest that there are at least five different notions of the 'true value' of an asset in finance theory, and argues, consistent with de Bruin et al. that in many cases the calculation of such values "makes impossible information demands on our knowledge of future dividends and returns" (McCauley (Dynamics of markets-econophysics and finance, Cambridge University Press, Cambridge, 2004). This paper explores some of the subjective elements involved in calculating the intrinsic value of an asset, and their implications for the Law of One Price. The Law of One Price states that investors should not pay different prices for the same investment. Consequently, the existence, and persistence, of arbitrage opportunities is often attributed to investor irrationality. However, if subjectivity is involved in the calculation of intrinsic value then two investors can, rationally, disagree about the value of a security. This implies that arbitrage opportunities may not always be instances of irrationality, or genuine mispricing, but reflect different investor's perceptions of the security. In economics, value is taken to be subjective, and Postigo (Axiomathes 27:591-576, 2017) describes how goods have value because of the role they play in the satisfaction of our needs. By applying this to finance, this paper will argue that a security can play a number of roles in a portfolio, depending on an investors' strategy. Given these different roles, different investors will be working with different data in their assessment of intrinsic value. In order to establish that an arbitrage opportunity exists it is therefore necessary to understand what information is relevant to pricing the investment in different locations, or markets. It may, in fact, be the case that the same security can trade at different prices because different investors do not see it as the 'same thing' at all. This analysis can also be used to throw doubt on the emphasis that fundamental analysis receives in discussions of rationality.
\end{abstract}

Keywords Finance $\cdot$ Information $\cdot$ Arbitrage $\cdot$ Law of One Price $\cdot$ Rationality

\section{Information in Financial Markets}

The existing literature provides reasons for doubting the idea that data, or information, in financial markets is objective, or neutral, with respect to the users of this data. For example, Ippoliti describes data as "theoretical objects", arguing that there is no such thing as 'raw data' in financial markets (2017a, p. 180). He writes that data is the output of an interaction between models, theories and mechanisms which, he argues, is what makes the study of market microstructure so fruitfull (Ippoliti 2017b,c). Models and theories about financial instruments also sometimes perform markets. The

Catherine Greene

c.m.greene@1se.ac.uk

1 LSE, London, UK idea of performativity in financial markets owes much to Mackenzie's (2008) argument that pricing models of financial derivatives affected the pricing of these derivatives so that they conformed to the models (Although see Brisset (2017) and Zuckerman (2013) for critical evaluations of performativity). Ippoliti describes the process as one where practitioners' use of certain tools affects markets, and also discusses how cognitive biases can affect the use of data (2017a, p. 181). Most relevant for this paper is his observation that a concern with the use of data arises from the need to identify what data is relevant to pricing a security. He discusses the prediction of recessions, arguing that economists have a large quantity of data at their disposal, which makes it difficult to separate signals from noise. He writes, "The possible indicators that seems (sic) to fit past data are so many that the underdetermination of hypotheses by data 
grows exponentially" (2017a, p. 190). He highlights two issues; the first is that the data that is relevant changes from one economic cycle to another; the second is that because data are used to implement policies reflexivity is a problem. Deciding which data is relevant is a difficult problem. The following section will apply this observation to the pricing of financial securities, where a distinction between data and information will be proposed.

The Efficient Market Hypothesis (EMH) postulates that the prices of securities traded in financial markets fully reflect all available information. There are three versions of the EMH- the weak form states that market prices should be independent, the semi-strong that prices should reflect all public information, and the strong form states that prices should reflect all information, including private information. If markets do, in fact, fully reflect all available information, then it must be clear what 'information' is. Greene (2019) notes that discussion of the EMH largely takes this as a given. In many cases it is apparently obvious what information markets should reflect; earnings announcements by companies are seemingly uncontrovertially 'information' for the price of that that company's equity. However, there are reasons for thinking that, as with Ippoliti's economics example, it is often difficult to decide what data is relevant. Preda writes that we need to understand "the factors and forces which define what constitutes a signal..." (2009, p. 82). He sees this as part of understanding the community of financial practitioners, arguing that what although we might understand price data from the nineteenth century as signals, we cannot separate what this data means from the understanding of financial markets at the time. Similarly, what constitutes relevant data "must be constituted through the agreement of the community of practitioners." (2009, p. 83). In other words, the 'information' that markets should reflect depends on the practices of the financial community making use of this information. Sornette (2002) also suggests that market prices contain information on impending crashes, which most traders have not managed to decipher. He suggests that the market can show emergent behaviour; behaviour at a macro level that is not reducible to micro level behaviour. If true, this considerably complicates how the idea of 'information' is to be understood.

The EMH takes it as given that 'information' is incorporated into market prices, but the discussion above suggests that there are two problems with this assumption. Firstly, there is a social dimension to information- the information relevant to pricing securities depends on the people doing this pricing. Secondly, if Sornette is right, there may be information in market prices of which most market participants are unaware. The literature therefore provides a number of reasons for thinking that the determining what information is, is not as simple as suggested by the EMH.
This paper add to this discussion by arguing for a framework for distinguishing between data and information.

Greene applies Skyrms' (2013) analysis of information to financial markets to make a distinction between data and information. For Skyrms, information is a signal that affects the probabilities of the receiver of a signal. His focus was on the evolution of sender-receiver games, but his framework can be applied to financial markets, where investors are usually concerned with probabilities of security prices rising or falling. Applying Skyrms' framework to financial markets suggests that information is data that moves investors' probabilities. Skyrms writes that "The informational content of a signal consists in how the signal affects probabilities. The quantity of information in a signal is measured by how far it moves probabilities." (Skyrms 2013, p. 34, italics in original). Applying this to financial markets; if a company releases annual sales data, this is information for investors in the company's equity because it leads them to revise their assessment of the probability of the stock price rising or falling. Investors have three possible actions they can take with regard to a financial investment; they can buy, they can sell, or they can do nothing. They have access to a wide range of data, some of which may be relevant for their investments. Data that leads investors to alter their probabilities about security prices rising or falling is information. Investors can therefore be seen as responders to information. (Greene 2019, p. 7). Markets contain and produce a lot of data, but this only becomes information when it changes investors' probabilities.

\section{Framing and Strategies}

The previous section introduced the distinction between data and information. This section will argue that different investors may use different data when evaluating the same security. The literature on framing illustrates how different investors can view the same investment in different ways, and how this affects their response to new information. Beunza and Garud (2007) describe differences in the way Amazon was analysed pre-2000; those who framed it as an internet company, comparing it with Dell, generally had a buy recommendation for the firm. Those who framed it as a bookseller, comparing it with Barnes and Noble, had sell or hold recommendations (2007, pp. 14-15). Beunza and Garud write that a Baysian model suggests that analysts should update their probability assessments in the same direction when new information becomes available. However, the Amazon example illustrates that analysts updated their probabilities in different directions, and that this is explained by the different frames these analysts used. In April 1999, Amazon announced larger losses than expected. For the analyst framing Amazon as a bookseller this was evidence that its' 
business model wasn't working. For the analyst who framed it as an internet stock these losses weren't relevant as he focussed on future value. They summarise, "The theoretical lesson here is that in contexts of ambiguity, when different and inconsistent bodies of meaning are available to explain the same set of news, analysts accord meaning to it with recourse to their existing frame." (2007, p. 29). In other words, different frames can lead analysts to respond differently to the same information. Wansleben (2013) suggests that we need to move beyond discussion of framing and classification in understanding financial markets, and the work of analysts. He suggests that one area for further work is hedge funds. While this paper does not deal with the specifics of analysts' work, it provides an additional way in which the same investment can be seen in different ways. This is illustrated by analysing the role an investment plays in hedge fund's strategies. Greene argues that the same data is not information for all investors. She writes,

"Investors pursue many different strategies, and buy securities for many different reasons. What counts as information for an investor following one strategy may not count as information for an investor following a different strategy. In other words, an earnings announcement may significantly affect one investor's assessment of the probability of a security price rising, but leave another investor's probabilities unchanged. To be clear, I am not just saying that both investors interpret the significance of the information differently, or that they disagree about the importance of the information; I am also saying that for one investor it does not count as information because it has no informational content in the sense of Skyrms' framework: it does not move the investor's assessment of the probability of the stock price rising." (Greene 2019, pp. 7-8)

The following example is intended to illustrate her argument. Suppose there are three types of investor participating in a market. The first is a fundamental equity investor, who analyses fundamental information about companies to determine what they should be worth. The second is a macro investor who invests in securities on the basis of macroeconomic information, including exchange rates, trends in GDP, and political trends. Usually, such an investor will invest in a broad range of financial instruments including debt, currencies, equities, and derivatives. The third investor is an arbitrage investor, who aims to capitalise on changes in historical relationships between security prices. This might include a disparity between the price of the same company listed on different stock exchanges. It could also include taking advantage of correlations between securities moving out of an historic range. These three investors will look at different data- the macro investor has primary interest in data on macro-economic trends, the equity investor primarily analyses company specific data, while the arbitrage investor is more concerned with statistical data. In a very general way, these strategies illustrate a different way in which a security can be 'framed', and the discussion that follows is intended to illustrate this.

Let us suppose that each of these investors own the equity of Company A, a mining company, and assign the following probabilities to the stock price rising over a certain time period:

Macro investor (70\% probability that the price will rise $10 \%$ within the next 3 months). This investor owns the equity of Company A as part of a trade intended to capitalise on rising commodity prices. Company A will benefit from this, as will the mining sector as a whole. The Macro investor has therefore bought a basket of commodity stocks, including Company A. Greene (2019) notes that although it is unusual for macro investors to buy equities directly because they generally by futures and other derivatives, this assumption is not prohibitively restrictive.

Equity investor (60\% probability that the price will rise $10 \%$ within the next 3 months). This investor owns the equity of Company A because they are optimistic about the management's ability to restructure the company to reduce costs. This investor uses bottom up analysis of companies to decide which to buy. They therefore hold Company A, but no other mining stocks.

Arbitrage investor (75\% probability that the price will rise $10 \%$ within the next 3 months). This investor monitors the correlation between the prices of equities and takes advantage of changes in these correlations. Company A's equity has, historically, had a $90 \%$ correlation with the equity price of a company in the same sector. This investor bought the equity of Company A on the expectation that the prices of these two equities would return to their historic relationship. They bought the equity of Company A, and sold short the equity of the other company.

Let us then suppose that the following data becomes available and assess the difference it makes to the investors' probabilities.

\section{The Rolling Correlation Between Company A and a Similar Company in the Same Sector has Moved from $85 \%$ to $75 \%$.}

Macro investor: the macro investor is not monitoring this data, and may even be entirely unaware of it. This data makes no difference to their probability assessment of the stock price rising.

Fundamental equity investor: the equity investor also does not monitor this data and may even be entirely unaware of it. This data makes no difference to their probability assessment of the stock price rising.

Arbitrage investor: the expectation of a continuation of the historic high correlation between the two stocks motivated their trade. This data is critical for this investor 
and they revise their probability of the stock price rising downwards.

Company A's Management Team Announce that Their Cost Cutting Measures Have Been Successful.

Macro investor: the macro investor will welcome the data, but it does not directly affect their motivation for investing in Company A. This data has no material effect on their probability assessment of the stock price rising because they believe the price will be driven by commodity prices.

Fundamental equity investor: the cost cutting scheme has a material effect on their valuation model for Company A. The equity investor raises their probability of the equity price rising.

Arbitrage investor: unless this data changes the relationship between Company A and other equities in the same sector this is unlikely to change their probabilities.

This example illustrates that different data is relevant for different investors, and, in contrast with the Amazon example, that some data is not information at all for some investors because it fails to change all investors' probabilities. Needless to say, the fully differentiated picture painted above is incomplete because the fundamental equity investor is likely to incorporate rising commodity prices in their valuation model for the company at some point. Nevertheless, forecasting commodity prices, and investing on the basis of such forecasts usually falls within the remit of macro investors, rather than fundamental equity investors.

Differential information has some interesting implications. Greene discusses the implications this has for the $\mathrm{EMH}$, and in particular the problems it poses for tests of the EMH. However, the EMH is not the focus of this article. If true, the existence of 'differential information' also implies that the Law of One Price is untrue, unless significant limiting assumptions are made. The remainder of this article firstly reviews what arbitrage is, before assessing the implications of differential information.

\section{Explaining Arbitrage}

The simplest arbitrage is when a security trades at different prices in two places. Buying at the cheaper price and selling at the higher price brings these prices together, so that the security trades at the same price in both places. Billingsley (2006) defines arbitrage as "the process of earning a riskless profit by taking advantage of different prices for the same good" (Understanding Arbitrage, p. 7, italics in original). Clearly, the 'same' investment should have one price. However, what makes two investments the 'same'? Arbitrage theory is used to construct new financial instruments, which are priced on the basis of the prices of their constituent parts. Arbitrage theory suggests that an investor should pay the same price for the set of underlying investments as for the security that is constructed using them. O'Hara (2016) writes that, "the building blocks of modern finance are not securities themselves or particular financial contracts, but rather the underlying cash flows that they create." (O'Hara, p. 16). Billingsley puts it slightly differently, "the 'same' investment must have the same price no matter how that investment is created" (2006, p. 3). (In 1958, Modigliani and Miller argued that a firm's value is independent of its capital structure i.e. the split between debt and equity. So, from an investor's point of view, it does not matter whether a firm is financed with debt (and leverage) or with equity.) Billingsey calls this the Law of One Price. He writes that identical investments can be created using different securities. He writes, "These investments must have the same expected cashflow payoffs to be considered identical" (2006, p. 3). In other words, in this case, what makes financial instruments the 'same' is providing investors with the same expected cash flows.

There is an obvious problem with this conception of what makes investments the 'same'. A bank may create a derivative that has cash flows identical with another financial asset. If investors are worried about the financial health of the bank they may not pay as much for the derivative because they are worried about the ability of the bank to pay out these cashflows. So, in addition to the same cashflows we need the same risks associated with these cash flows. In other words, the 'same' assets have the same cash flow and risk profile. Billingsley writes "securities are the 'same' if they produce the same outcomes, which considers both the expected returns and risk" (2006, p. 6).

MacKenzie writes that what counts as similar risk is difficult to judge, and often contentious; "The practice of arbitrage can, indeed, be seen as hinging on the identification of similarity that is 'good enough' for practical purposes" (2008, p. 224). He adds that a crucial issue for arbitrage is the determination of what counts as 'sufficient similarity' (2008, p. 271). Hardie and MacKenzie (2013) describe similarity judgements as theory dependent. The theories used to evaluate an arbitrage opportunity may be mathematical or "vernacular and down to earth" (2013, p. 194). They describe both the role such theories play in driving similarity judgements, and their role in convincing others that an arbitrage opportunity exists. In other words, the existence of an arbitrage opportunity is not identified on the basis of objective analysis of independent data; it is identified by a community of practitioners coming to see different investments as sufficiently similar. To summarise, the Law of One Price suggests that 'the same' investments should trade at the same price. The discussion above has illustrated the subjectivity inherent in judgements of similarity, or sameness. The following section argues that the use of differential information means that investments that appear to be the same, may not be the same thing at all. 


\section{The Implication of Differential Information for Arbitrage, and the Law of One Price}

The following section extends the example above to illustrate the implication of differential information. Let us suppose that the equity of Company A is listed on stock exchanges in two different countries; Country 1 and Country 2. Further, let us suppose that in Country 1 the equity of Company A is primarily held by arbitrage investors, while in Country 2 the equity of company A is primarily held by fundamental equity investors. The equity of Company A trades at different prices in Country 1 and Country 2. What are we to make of this?

In this case, the investment- the equity of Company $\mathrm{A}$, is the same thing in both places. It represents an equity stake in Company A. To make things simple, let us also assume that the shares listed in Country 1 are convertible into the shares listed in Country 2, and vice versa. A difference in the price of these shares therefore represents an arbitrage opportunitya security with the same cash flows and the same risk profile is trading at different prices. It should be possible to make a profit by buying the cheaper equity and selling the more expensive equity.

However, things are not necessarily as simple as this. Investors in Country 1 primarily hold the equity of Company $\mathrm{A}$ on the expectation that the correlation between the equity of Company A and another company in the same sector will return to its long-term average. The fundamental equity investors in Country 2 hold the equity of Company A because it is much cheaper than other companies in the same sector, and the management team have announced that they will restructure the company to make it more efficient. Investors in Country 1 and Country 2 have bought the equity of Company A for different reasons, and, if the argument above is correct, different data will be information for the purposes of their investment strategies. The two types of investor hold the equity of Company A to benefit from different factors- a return to a historical statistical relationship between two equity prices, or corporate restructuring. The bottom up equity investor is very unlikely to sell the equity if its correlations with other companies share prices change. Similarly, the arbitrage investor is unlikely to sell the equity of Company A if the management team announce delays to their restructuring plans.

Does an arbitrage opportunity exist in this case? In a superficial sense, yes- the same thing is trading at different prices. However, if we take differential information into account it isn't clear that the equity of Company A is, in fact, the same thing for investors in Country 1 and Country 2.
This appears counter intuitive. How can the listed equity of the same company be a different thing in different locations? It is different because the equity has been bought not because it represents ownership in Company A, but because it is a financial tool that enables investors to profit from different factors. Specifically, for the arbitrage investor it is a way to profit from a change in equity price correlations, while for the fundamental equity investor it is a way to profit from developments specific to Company A. An investor seeking to capitalise on this arbitrage opportunity may find that the pricing differential between the equity of Company A persists because the two types of investor view the investment in different ways, and continue to view it differently.

This is a simple example, but not too far removed from real life cases. Hershberg (2012) notes that 'twin stocks', which are "stocks with claims to almost identical dividend streams can trade at significantly different prices". He also writes that stocks of parent and subsidiary companies can trade at prices that are out of alignment with the relationship between these stocks. He discusses the example of Royal Dutch and Shell Transport in more detail. These two companies merged on a 60:40 basis in 1907, while remaining separate companies. Therefore, shares of Royal Dutch are a claim to $60 \%$ of the total cash flows, and shares of Shell Transport are a claim to $40 \%$ of these cash flows. The market value of the equity of Royal Dutch should therefore be 1.5 times the market value of Shell. However, Royal Dutch has traded between $35 \%$ undervalued and $15 \%$ overvalued, relative to the price of Shell (2012, p. 17). This paper makes no claims about the reasons for this mispricing. The Shell example merely demonstrates that the hypothetical example is not prohibitively unrealistic because the 'same', or very similar, security in terms of risk and cash flow profiles can trade at different prices for extended periods.

To summarise, if we take the idea of differential information in financial market seriously, then this means that arbitrage opportunities may not simply be instances of mispricing. Where investors use different data as information in their strategies they may, rationally, view the 'same' security differently. Two components of this argument need further elaboration. Firstly, the link between irrationality and arbitrage, and secondly, the idea that listed equities can be viewed differently, depending on an investors' strategy. These are dealt with in turn.

\section{Differential Information and Investor Rationality}

Hershberger cites Thaler and Barberis to highlight one of the risks to exploiting arbitrage, which is that "whatever investor sentiment is causing one share to be undervalued relative to the other could also cause the share to become even 
more undervalued in the short term" (Hershberg 2012, p. 17). Scruggs (2007) attributes the mispricing of Royal Dutch and Shell to noise trading. He makes a number of distinctions that are helpful. He defines noise trading as "Trading that is uncorrelated with changes in fundamental or intrinsic value" and also that noise trading may occur for exogenous reasons, such as portfolio rebalancing or liquidity needs, or when investors "trade on noise (e.g. sentiment) as if it were information" (Scruggs 2007, pp. 76-77). In other words, arbitrage opportunities may persist when investors trade on sentiment as if it were information, or when they trade on the basis of non-fundamental data, such as portfolio rebalancing.

Scruggs assumes that it is clear that sentiment is not information. If it is clear what data is information, then trading on the basis of data that is not information is sentiment, or 'noise trading'. Wu et al. (2017) go further, writing that "Investor sentiment is considered to be a belief about future cash flows and investment risks that are not justified by the facts at hand" (2017, p. 3). However, this is not the only way we can interpret this situation. To simplify, we have a model of the value of Royal Dutch and Shell, and the value that this model gives us changes over time as new information is incorporated into the model. However, the share price does not always change in line with our model. There are two ways in which this can be interpreted; firstly, as evidence that investors are trading on noise, or for external reasons, secondly, that the model does not incorporate all the information investors are using to determine whether to trade. The first interpretation privileges fundamental analysis, but, as we have seen, not all investors are fundamental investors. Scruggs suggests that this is a possibility, he writes, "It is unclear whether the unexplained return variation reported in these papers is due to noise trading, or whether the empirical models do not fully account for all information relevant for valuation" (2007, p. 77). Similarly, Rashid (2007) hints that 'information' is a problematic concept. He discusses one formulation of the law of one price: As information about a commodity improves, its price variability will decline. Rashid notes that "Such a reformulation does not necessarily make the new law more testable since the difficulties of measuring 'information' and its 'spread' are at least as great as those of measuring the LoP at present" (Rashid 2007, p. 81). Unfortunately, Rashid does not elaborate on these difficulties.

The persistence of arbitrage opportunities is usually attributed to noise trading, but it seems that investors do so surprisingly often. Rashid (2007) reviews some examples including Lutz (2004) who suggests that deviations from the law of one price are observed in the European car market, and Haskell and Wolf (2001) who argue that there is variability in the price of similar consumer goods in the US. Rashid reviews literature discussing similar pricing anomalies in the commodities markets (Rashid 2007, p. 79), and concludes with a quote from Williamason and Milner "The hypothesis that arbitrage quickly equates goods prices internationally has probably been rejected more decisively by empirical evidence than any other hypothesis in the history of economics" (Rashid 2007, p. 80).

What are we to make of this? Sing, in a review of the behavioural finance literature begin by noting that traditional finance assumes that investors are rational, but that often, investors behave emotionally, rather than rationally (2010, p. 1). This suggests that irrationality means acting on emotions. Baker and Wurgler (2013)) describe the rationality of agents within corporate finance in the following way: "Agents are supposed to develop unbiased forecasts about future events and use these to make decisions that best serve their own interests" (p. 358). Hershberg (2012), citing Thaler and Berberis, defines rationality in the following way. An agent is rational if, when they "receive new information, they update their beliefs correctly, in the manner... consistent with Savage's notion of Subjective Expected Utility" (2012, p. 11). The details of utility theory are beyond the scope of this paper however, according to the definitions here, investors are rational when they take account of all the available information and calculate the risk and expected returns of a security in a way that reflects this information. The idea of rationality therefore depends on agreement about what the relevant information is.

If we want to show that an investor is irrational, then we must firstly agree about what the relevant information is that they should be taking account of. As the example above has sought to demonstrate, this is not always as easy as it seems, because it depends on why an investor has invested in a security. Behavioural finance has discovered a number of ways in which investors are not rational (The Handbook of the Economic of Finance has a good overview of the literature in Chapter 22), but this, again, is not the focus of this paper. The focus here is on the difficulty in deciding what it means for an investor to be rational. If investors make use of differential information, then two investors can, rationally, differ in their belief about what information is relevant to deciding whether to buy or sell a security. Zuckerman (2004) argues for a similar point of view. He notes that stocks are evaluated by reference to industry classifications, but that stocks vary in how neatly they fit into a classification. Some stocks are therefore classified, and analysed, heterogeneously. He writes, "the arrival of material information should stimulate more trade when the stock is incoherent because investors in such stocks are more likely to vary in the models they use to interpret such news" (2004, p. 413). In other words, when stocks are viewed heterogeneously analysts will interpret new information differently. This paper argues that the heterogeneity extends beyond classification, and that when stocks play a different role in investor's strategies they can disagree about what the relevant information is. 
A caveat is required here. Two investors using the same information to decide what an investment is worth may also disagree about the value of a security. This can be for any number of reasons, including disagreements about the significance of information. The point argued for here is that disagreements about information extend beyond disagreement about the significance of a specific piece of information. Different investors may be looking at entirely different information. In order to judge whether an investor is rational we must firstly be clear what data they consider information. This is not to say that fundamental data is entirely irrelevant because if company performed so poorly that it goes into bankruptcy this would significantly impact the correlation between its' share price and the share prices of other companies. In the normal course of events however, fundamental data is not something that the arbitrage investor need concern themselves with.

It might be responded that, indeed, any trading strategy that does not focus on fundamental information is irrational. However, strategies not based on fundamental analysis are profitable, so it is difficult to countenance the view that investors pursuing these strategies are irrational, except in a very limited sense in which 'rationality' is defined by reference to fundamental information. Furthermore, there is evidence that the noise trading effect varies over time. Scruggs writes that the effect of noise trading was high following the failure of LTCM in 1998 and and peaked during the collapse of the tech bubble in 2000 (Scruggs 2007, p. 80). This suggests, although it requires further empirical investigation, that data about shocks to the financial system (in the case of the LTCM), or dramatic market dislocation (in the case of the collapse of the tech bubble) becomes information for a large number of investors who, in more benign times concentrated on fundamental, or other, data. In effect, their usual information is swamped by information about such shocks. A simple example might illustrate what is going on. For a short period after a large natural disaster the only data that is information is about the extent of the disaster. It may take some time for investors to turn their attention to any other data. If fundamental data is all that matters, this is irrational to the extent that the disaster does not affect the fundamental performance of a company. However, given extreme uncertainty, the only data that is information is data about the disaster.

One worry with widening the notion of rationality in financial markets is that it appears to countenance any data as information, as long as some investors are using it. There may be investors using astrology, or those infamous monkeys with darts, to inform their investment strategy. Does this mean we are committed to accepting these investors as rational? We need to distinguish between the rationality of an investors' strategy, and the rationality of their responsiveness to information. An investor using an investment strategy based on dart throwing monkeys will be rationally responding to data, if they incorporate all the data that is relevant to their strategy. This does not mean that their strategy itself is rational. However, if an investor generates consistent returns using a monkey-based strategy, then I see no particular worry with accepting that this strategy is rational, with the caveat that the reason for its success is a mystery. Perhaps those monkeys know more than we give them credit for.

In conclusion, the traditional view of financial markets contrasts fundamental trading with noise trading, with the implication that deviations from fundamental value are a failure to respond to relevant information. This privileges fundamental analysis and its importance for valuation and capital markets. This rationality by fiat strategy is unjustified because different types of investors may be using other data as information for the purposes of their strategy. However, a caveat is required here; investors may agree about what fundamental data is relevant to determining the fundamental value of a security, but disagree about whether this is information for the purposes of trading in a security. Specifically, the arbitrage investor may, if asked, agree with the fundamental equity investor about what information is required to calculate the fundamental value of the company but this does not mean that this is information for the purposes of trading the equity of that company. The following section reviews the idea of subjective value in economics with the aim of clarifying this distinction.

\section{Subjective Value and Economics}

In economics, it is widely accepted that value is subjective, but it is not always clear what economists mean by this. Postigo (2017) writes, "All economists today accept that value is subjective." (2017, p. 562). The standard interpretation is that economic value measures how much someone is willing to pay for a good. This willingness to pay is determined by the goods that must be forgone to make this purchase. Postigo's concern is that this describes a process of valuing by an agent, but does not illuminate what has value to this agent, namely the good they decide to buy.

Eabrasu writes that "the meaning of subjective value remains equivocal and imprecise." (2011, p. 216). She begins with a definition of subjectivity. Choice is made in an environment of scarcity; but scarcity, in and of itself, does not tell us whether value is subjective. It simply tells us that choices must be made. Value is subjective if "we admit that the values are the outcome of the preferences effectively demonstrated in the course of their actions. Conversely, the theory of value is objective if we consider that the values of the ends to be pursued by the agent are ordered independently of their effective preferences." (2011, p. 219). Postigo understands subjective value in a similar way. $\mathrm{He}$ 
reviews the origins of subjective value theory, proposed by Menger, as an alternative to the view that the value of a good is determined by the costs the costs of producing it. Menger proposed that value "is the importance that individual goods or quantities of goods attain because we perceive these as the causal factors to the satisfaction of our needs in concrete choices." (Postigo 2017, p. 563). This notion of value has two components, the opportunity cost of choices foregone, and the role the goods under consideration play in the satisfaction of our needs. Postigo calls this the "intentional content" of a choice which "is shaped by the particular present need for which each alternative is evaluated." (2017, pp. 565-566). This choice results in a good having value.

However, Postigo notes that, in modern economics textbooks, value is not understood in this way, despite it being described as subjective. Value is calculated on the basis of a comparative calculation of costs versus benefits for the alternatives under consideration (p. 567). "All value is expressed according to rational choice theory, and there is no need for a theory of value" (p. 568). Ebarasu makes this distinction more explicit. Neoclassical economists usually agree that subjective value theory is underpinned by subjective preferences. However, in the Austrian conception, value only emerges through intentional action; value is tied to preferences that are demonstrated through real choices. This means that "prices emerge only after the effective action of buying and selling. Objectivists maintain that the price can be determined independently of the real action, by looking at the costs of production, the intrinsic utility of the exchanged good, the imagined individual preferences, etc.” (p. 221).

This discussion has an interesting implication for financial markets. If we countenance the role intentional action has in determining the value of a good, in other words, that goods have value for agents because of the role they play in the satisfaction of their needs, then this provides an underpinning for a theory of subjective value in financial markets. Securities have value for investors due to the role they play in their different investment strategies. These strategies dictate what data is information for an investor pursuing these strategies. If true, this means that assets with identical cash flows may indeed be different things for investors using different strategies. Investors believe those cash flows, and the risks associated with these cash flows, to be contingent on different factors. The arbitrage investor buys the equity of Company A because it provides exposure to changing correlations between it and other equities. The fundamental equity investor buys the equity of Company A because of changes in the fundamental features of the underlying company. While both investors may believe that the price of Company A will rise, they believe this rise is contingent on different factors. For the arbitrage investor it is a return to an average level of correlation between Company A and other stocks, for the fundamental equity investor it is the restructuring of the company and the risks they associate with these returns are entirely different.

This characterisation may seem counterintuitive given that although economic goods can satisfy a range of needs, the equity of a company is just a financial interest in that company, and the performance of that underlying company depends on the fundamentals of that company. While it is true that the equity of a company does represent the right to cash flows from that company, when it is listed on an exchange it also becomes a financial instrument that can play a number of roles, or satisfy a variety of needs, within an investment strategy. Furthermore, there are reasons to believe that the very notion of the 'fundamental value' of an equity reflects investors beliefs about equity markets, rather than an objective calculation of value. This is because the way the fundamental value of equities has been calculated has changed significantly over time. Rutterford (2004) reviews the changes to equity valuation models in the US and UK and concludes that "once accounting and taxation difficulties have been dealt with, it is market levels which are a primary influence on the popularity of particular valuation techniques (2004, p. 143). Although fundamental analysis appears to provide an objective value for an equity, the valuation methodologies have changed significantly over time. If Rutterford is correct, this is not due to increasing accuracy, but a response to market levels.

\section{Conclusion}

De Bruin and Walter (2017) note that, despite evidence that many of the assumptions made by traditional finance are questionable, they continue to be used in theory, and by practitioners. The examples they discuss include the assumption of normality of market returns, and the tendency of volatility to cluster (large moves are more likely to follow other large moves, and vice versa). This paper has sought to question the assumptions underpinning the Law of One Price, by arguing that it rests on a simplistic understanding of information in financial markets. Building on the idea of 'frames', it argued that the same security can be seen as different things, depending on the role it plays in an investor's strategy. If true, this has a number of implications for the standard understanding of financial markets:

First, that when a security plays different roles in investment strategies, or portfolios, different data is information for evaluating this security.

Second, that if investors use different data to determine whether to buy or sell a security they may be willing to pay different prices for this security.

Third, that the persistence of arbitrage opportunities may therefore not be instances of irrationality, or the effects of 
'noise' trading, but reflect the use of differential information by investors.

Fourth, that the law of one price is therefore only a law if all investors are using the same information to decide whether to buy or sell a security.

\section{Compliance with Ethical Standards}

Conflict of interest I declare that there is no conflict of interest.

Research Involving Human and Animal Participants This article does not contain any studies with human participants or animals performed by the author.

Open Access This article is distributed under the terms of the Creative Commons Attribution 4.0 International License (http://creativeco mmons.org/licenses/by/4.0/), which permits unrestricted use, distribution, and reproduction in any medium, provided you give appropriate credit to the original author(s) and the source, provide a link to the Creative Commons license, and indicate if changes were made.

\section{References}

Baker M, Wurgler J (2013) Behavioural corporate finance: a updated survey. In: Constantinides GM, Harris M, Stulz RM (eds) The handbook of the economics of finance. Elsevier, Amsterdam, pp 357-423

Beunza D, Garud R (2007) Calculators, lemmings or frame-makers? The intermediary role of securities analysts. Sociol Rev $55(2): 13-39$

Billingsley R (2006) Understanding arbitrage: an intuitive approach to financial analysis. Wharton School Publication, Philadelphia

Brisset N (2017) On performativity: option theory and the resistance of financial phenomena. J Hist Econ Thought 39(4):549-569

de Bruin B, Walter C (2017) Research habits in financial modelling: the case of non-normality of market returns in the 1970s and the 1980s. Stud App Philos Epistemol Ration Eth 34:73-93

de Bruin B, Herzog L, O'Neill M, Sandberg J (2018) Philosophy of money and finance. In: Zalta EN (ed) The Stanford encyclopedia of philosophy. Stanford University, Stanford

Eabrasu M (2011) A praxeological assessment of subjective value. Q J Austrian Econ 14(2):216-241

Greene C (2019) Information in financial markets. In: Addis M, Lane PCR, Sozou PD, Gobet F (eds) Forthcoming in scientific discovery in the social sciences. Springer, Heidelberg (In Press)

Hardie I, MacKenzie D (2013) The material sociology of arbitrage. In: Cetina KK, Preda A (eds) The Oxford handbook of the sociology of finance. Oxford University Press, Oxford, pp 187-202

Haskell J, Wolf H (2001) The law of one price-A case study. Scand J Econ 103(4):545-558
Hershberg M (2012) Limits to Arbitrage: an introduction to behavioural finance and a literature review. Palermo Bus Rev 7:7-21

Ippoliti E (2017a) Dark data some methodological issues in finance. In: Ippoliti E, Chen P (eds) Methods and finance. Springer, Berlin, pp 179-194

Ippoliti E (2017b) Methods and finance. A view from inside. In: Chen P, Ippoliti E (eds) Methods and finance. A unifying view on Finance, Mathematics and Philosophy. Springer, Berlin, pp $121-128$

Ippoliti E (2017c) Methods and finance. A view from outside. In: Chen P, Ippoliti E (eds) Methods and finance. A unifying viewon Finance, Mathematics and Philosophy. Springer, Berlin, pp 3-15

Lutz M (2004) Pricing in segmented markets, arbitrage barriers and the Law of One Price: evidence from the European car market. Rev Int Econ 12(3):456-475

MacKenzie D (2008) An engine not a camera: how financial markets shape markets. MIT Press, Cambridge

McCauley JL (2004) Dynamics of markets-econophysics and finance. Cambridge University Press, Cambridge

O'Hara M (2016) Something for nothing: arbitrage and ethics on wall street, 1st edn. W.W. Norton \& Company, New York

Postigo GZ (2017) On the transformation of economic value: from its Austrian roots to contemporary economics. Axiomathes 27:561-576

Preda A (2009) Framing finance: the boundaries of markets and modern capitalism. University of Chicago Press, Chicago

Rashid S (2007) The 'law' of one price: implausible, yet consequential. Q J Austrian Econ 10(1):77-88

Rutterford J (2004) From dividend yield to a discounted cash flow: a history of UK and US equity valuation techniques. Acc Bus Financ Hist 14(2):115-149

Scruggs JT (2007) Noise trader risk: evidence from Siamese twins. J Financ Markets 10:76-105

Sing R (2010) Behavioural finance studies: emergence and developments. J Contemp Manag Res 4(2):1-10

Skyrms B (2013) Signals: evolution, learning, and information. Oxford University Press, Oxford

Sornette D (2002) Predictability of catastrophic events: material rupture, earthquakes, turbulence, financial crashes, and human birth. Proc Natl Acad Sci USA 99(3 Supplement 1):2522-2529

Wansleben L (2013) Financial analysts. In: Cetina KK, Preda A (eds) The Oxford handbook of the sociology of finance. Oxford University Press, Oxford, pp 250-271

Wu Q, Ying H, Jing L (2017) Investor sentiment, idiosyncratic risk, and mispricing of American Depository Receipt. J Int Financ Markets Inst Money 51:1-14

Zuckerman EW (2004) Structural incoherence and stock market activity. Am Sociol Rev 69(6):405-432

Zuckerman EW (2013) Market efficiency: a sociological perspective. In: Cetina KK, Preda A (eds) The Oxford handbook of the sociology of finance. Oxford University Press, Oxford, pp 223-249

Publisher's Note Springer Nature remains neutral with regard to jurisdictional claims in published maps and institutional affiliations. 